\title{
MedienPädagogik
}

Zeitschrift für Theorie und Praxis der Medienbildung

Special Issue Nr. 35:

Media literacy as intergenerational project: skills, norms, and mediation

Edited by Claudia Riesmeyer, Thorsten Naab,

Anne-Linda Camerini, Ruth Festl, and Christine Dallmann

\section{Mediating Media Usage in Times of Migration}

\section{Family Rules and Media Repertoires of Arab Refugee Children and Teens in Germany}

Liane Rothenberger, Ahmed Elmezeny, and Jeffrey Wimmer

\begin{abstract}
The use and regulation of mobile media devices of children and adolescents in refugee families is largely unexplored. Our qualitative approach utilizes in-depth guided interviews with parents and children in Arabic speaking refugee families in Germany. All interviewed families have resided in Germany from one to four years. The sample consists of both couples and single parents, while most children are in their final year of kindergarten, in primary school, or secondary school. The study explores the selection and usage of mobile media devices and content in their social context, such as the use of social media platforms and apps at home and for school. Our research highlights changes in mobile media usage after the interviewees' arrival in Germany due to the different socio-cultural environment and a changed media agency. The amount of change greatly depends on the age of the children, for example, the younger they were when arriving in Germany, the less likely they are to use mobile media to stay in touch with their former friends. Additionally, most children and adolescents tend to consume German media content more often than Arabic content. In the rare cases they do consume Arabic media content, it is in the presence of their parents, who state that they do so to bring their children closer to their roots.
\end{abstract}

Die Vermittlung von Mediennutzung in Zeiten der Migration. Familiäre Vorschriften und Medienrepertoires von arabischen geflüchteten Kindern und Jugendlichen

\begin{abstract}
Zusammenfassung
Die Nutzung und Regulierung mobiler Medien von Kindern und Jugendlichen in Flüchtlingsfamilien ist weitgehend unerforscht. Einem qualitativen Ansatz folgend führten wir Leitfadeninterviews mit Eltern und Kindern in Arabisch bzw. Deutsch. Alle befragten Familien leben seit ein bis vier Jahren in Deutschland. Die Stichprobe besteht aus Paaren und Alleinerziehenden, wobei sich die meisten Kinder im letzten Jahr des Kindergartens, in der Grundschule oder der Sekundarschule befinden. Die Studie untersucht die Auswahl und Verwendung mobiler Mediengeräte, insbesondere Smartphones und Tablets, und deren Inhalte im sozialen Kontext, beispielsweise die Verwendung von Social-Media-Plattformen
\end{abstract}


und Apps zu Hause und für die Schule. Unsere Studie verdeutlicht Veränderungen in der Nutzung mobiler Medien nach der Ankunft der Befragten in Deutschland, was auf das veränderte sozio-kulturelle Umfeld und mediale Handlungsfähigkeiten zurückzuführen ist. Das Ausmass des Wandels hängt stark vom Alter der Kinder ab. Ein Beispiel: Je jünger die Kinder waren, als sie nach Deutschland kamen, desto weniger wahrscheinlich nutzen sie mobile Medien, um mit ihren ehemaligen Freund*innen in Kontakt zu bleiben. Ausserdem konsumieren die meisten Kinder und Jugendlichen häufiger deutschsprachige Medieninhalte als arabische. In den seltenen Fällen der Rezeption arabischer Medieninhalte geschieht dies in Anwesenheit der Eltern, die wiederum angeben, dies zu tun, um den Kindern ihre Wurzeln näher zu bringen.

\section{Introduction}

"Yesterday the motto was: immigrate and cut your roots; today it would be circulate and keep in touch", Diminescu $(2008,568)$ notes from her studies with migrants. Ten years ago, the tendency to change modes of communication could already be observed. To date, this has matured into the manifold mediation processes, which play a fundamental role in today's migration situation. Fast-communicative networking through technological innovations in media has a considerable influence on the interaction of refugees. Diminescu coined the term «connected migrant» $(2008,568)$, which leads to the key question: How do media and communication influence the lives of ethnic minorities in new cultures?

In a qualitative study, Díaz Andrade and Doolin $(2016,409)$ have identified key factors in how media support the social integration of refugees: communicating effectively when participating in an information society, understanding the new host society, being socially connected, and expressing one's own cultural identity. The study of Friedrichs-Liesenkötter and Schmitt $(2017,2)$ shows prototypically that media and communication play an ambivalent role as agency mediators:

"they are 'escape agents', make everyday life in a new environment easier, and link young refugees to people involved in civic engagement. Furthermore, they strengthen young refugees' possibilities to articulate themselves and to participate; enhancing media literacy of young people in media-educational projects».

The role media plays in the lives of the diaspora has since then been the subject of extensive research. Immigrants utilize old (television, radio, print) and new (Internet, social) media from both their current and original cultures for a variety of reasons. Studies show that 'ethnic' media usage by individuals from a diaspora contributes heavily to their identity construction, and that the usage of online media to establish connections to similar individuals can recreate (or strengthen) a sense of community 
(Rinnawi 2012). However, from the perspective of current digital media change, the question of the role of media in societal integration processes of migrants is more relevant than ever, especially with the rising fears of extensive fragmentation processes (see Jandura et al. 2017 for an overview). Moreover, the media literacy of migrants, especially in how they navigate the digital media world, has been a neglected field in migration research. This is a serious shortcoming because the «self-determined selection of media offerings for the fulfilment of individual and social needs, as well as coping with the associated risks, are in view of the far-reaching mediatization process: a basic requirement for democratic societies» (Paus-Hasebrink and Hasebrink 2018, 6; personal translation).

Effective media literacy skills can act as protection against fake news, populism and other threats in society (e.g. Bulger and Davison 2018). Media literacy can in fact be a prerequisite to deal with media risks such as excessive usage, online bullying or shaming and phishing (e.g. Livingstone 2011). While media and their technologies are constantly changing, so is the social context of media usage, and the co-presence of actors of media socialization (parents, teachers, peers, siblings, etc.); making the establishment and maintaining of this knowledge a life-long task (Hurrelmann and Bauer 2018). A change of the media environment (migrating to another country) might lead to other dispositions towards media and media literacy, which makes refugees ideal candidates to observe changes in media preferences and literacy.

From a societal perspective, migration issues are of great relevance in Germany since it has one of the most culturally diverse populations in the world. There are various diasporas hailing from all over the globe with the largest diaspora being Turkish (1.527.118 individuals), while second and third are the Polish (866.855) and Syrian (698.950) diaspora (Amt für Statistik 2017). The number of Syrian and Arab immigrants will only steadily increase in Germany given the unstable political climate in the Middle East region. Arab culture, while diversified, still shares a lot of similarities (Hopkins and Ibrahim 2006), but is distinct from the German or European culture. This is why it can be assumed that Arab immigrants have possibly divergent media preferences and could also possibly practice distinctive media regulation with their children, based on cultural and religious values that might not be shared by European or other Western cultures (Molnàr 2008, 39f.). In the following study, we analyse how 20 refugee families, members of the Arab diaspora in the City of Erlangen (Germany), construct and regulate both their device and content media repertoires, in hopes of addressing gaps in migration research. 


\section{Theoretical framework}

Until recent years, there were not many studies on the media usage of the Arab diaspora in Germany. Rinnawi (2012) conducted one study that assesses the media used by both older and younger generations of the diaspora. He finds that the older generation (or what he calls the 'first generation') primarily uses television media, while younger individuals, who grew up in Germany and are computer-proficient, tend to utilize the Internet more. Rinnawi (2012) claims that access to Arab satellite broadcasting in the 1990s has strengthened the Arab identity of individuals in a process he calls 'Instant Nationalism'. Additionally, he discusses how the Internet serves as a 'cyber-mufti' or a religious authority (ibid.). While his study addresses a large gap in knowledge about media usage, it does not analyse how this media usage contributes to the diaspora's integration into mainstream German culture. In recent years, the increase of forced migration has also led to multiple studies, however; all are focused on specific media such as the smartphone, or specific usage situations and contexts, like the escape experience, and/or specific groups: mostly young migrants (Arnold et al. 2017; Fiedler 2016; Kutscher and Kress 2018; Richter et al. 2016).

As noted in Rinnawi's (2012) research, diasporas use multiple types of media in their daily routine. For our study, we address mobile media used by children in Arab refugee families in Germany as a part of the entire spectrum of media in use. Therefore, we utilize the holistic framework of media repertoires (Hasebrink and Popp 2006; Hasebrink and Hepp 2017). This concept is based on three main principles:

- User centred perspective: the media repertoire approach asks which media a specific individual uses instead of inquiring which audiences a particular medium reaches.

- Entirety: this approach stresses the need to look at the whole catalogue of media utilized by an individual and not at a single medium, which avoids faulty information that might be extracted from particular medium usage.

- Relationality: how different media are connected to each other is extremely important as this reflects that media repertoires are premeditated and significantly structured configurations of media, not just the sum of media used.

In addition to the theory of media repertoires, we also utilize previous work on transnational migration and media usage. Studies on transnational migration, not specifically focused on Arab populations, have empathized the importance of digital/ virtual media for gathering information, creating a safe space, a sense of belonging, shared experiences for migrants, or allowing freedom of expression (Gajjala 2004; Parham 2004; Wilding 2006; Hegde 2011). More recent studies have also «discussed visibility and the affordances of new technologies for strategic self-representation of migrants as networked agents and social forces» (Witteborn 2015, 1). In addition to these affordances, Witteborn $(2015,15)$ notes the process of becoming: «a process 
through which people shift between different moments and ways of being and relating while responding to historical, sociopolitical and economic realities, and moving towards new ways of experiencing and acting in the world». She states that new media technologies have a hand in this process, and that «technologically enabled sociability can foster individual and collective ways of knowing, relating and becoming for forced migrants» (ibid).

Concerning specific media devices, Horst and Taylor (2014) find that mobile devices are essential for migrants which are constantly crossing borders. Observing migrants from Haiti and the Dominican Republic, Horst and Taylor $(2014,166)$ find that mobile devices enable relationships (similar to other populations); however, due to constant movement across borders, these devices take on specific properties and abilities. For individuals that are always on the move, the absence of mobile phones is felt strongly. Additionally, it facilitates the coordination and movement of goods and people, and finally, «the phone can also act as a proxy for people through negating the need for physical mobility» (ibid 166), meaning that individuals no longer need to visit their relatives or perform official functions such as paying bills.

With the increase of mobile media usage comes a need for regulation also due to their ubiquitous nature in children's lives. Regardless of where you come from, Germany, Syria, or Iraq, each set of parents have a variety of ways of regulating their children's media repertoires and consumption. Zaman et al.'s (2016) mixed-method study of 24 Belgian parents and their 36 children between the ages of three to nine highlighted a range of such strategies. The research results note the role of contextual factors in minimizing children's exposure to risks and facilitating digital opportunities. Specific parental mediation strategies can be both supportive or restrictive and contradictory in nature, they are as follows (Valkenburg et al. 1999; Zaman et al. 2016):

- Restrictive mediation: restricting access to media either through time (duration or moments of access), device (usage, number or type), content (used and consumed), location (distance from TV, etc.) and purchase (budgeting, free apps only).

- Co-use: mediations here include being a helper and directing children while using a medium or being a buddy and partaking in certain media events together.

- Active mediation: similar to restrictive mediation, however active mediation involves interactions and discussions about time, device, content and purchase issues.

- Distant mediation: the final mediation strategy involves parents being remote from children's usage of media while still being somewhat aware; it includes both deference and supervision. Deference is giving independence to children and not intervening while supervision is allowing independent usage but under direct observation. 
It is important to note that both co-use and active mediation are considered a form of participatory learning, which highlight parents' investment in their children's digital literacy skills (Zaman et al. 2016, 12). Drawing on this pilot study, our qualitative case study wants to initially answer the question of how forced migration influences parental mediation strategies.

Additionally, we utilize Baacke's (1997) framework on «Medienkompetenz» to assess participants' media literacy. Baacke (1997) defines media literacy as the ability to adequately assess and use media technologies and/or content by observing individual's behaviour in the following four dimensions: media critique, media knowledge, media usage and media production. Concerning media critique, this concerns participants' ability to assess both the chances and risks media are able to provide, such as invasions to privacy or opportunities for positive self-presentation. The dimension of media knowledge deals with participants' knowledge of both the mediums, content and the technology itself; as well as how to operate and make us of it. Media usage, as a dimension, covers two aspects: concrete usage, which entails an individual's ability in being able to orient him/herself in the media world; for example, finding a specific program among a multitude of those provided, and use of interactive media; which encompasses all self-determined usage, such as writing letters to the editor, or using chatting programs. Finally, the dimension of media production deals with both the creation of media content, for either financial or entertainment purposes, as well as the collaboration with media. Collaboration does not necessarily have to result in the production of content, but individuals can also collaborate and share knowledge about certain aspects of media: such as laws, or programming, etc.

To assess Arab refugee families' media literacy and parental mediation strategies, we have formulated two research questions that identify these aspects in the family setting:

- RQ1: Which media literacy skills do family members of the Arab Diaspora possess?

- RQ2: How do different parental mediation strategies manifest in Arab Diaspora families?

The design of our case study ties in with the contextualizing perspective of the media repertoire approach; providing a user-centred perspective, which takes the entire repertoire and individual use (in relation to one another) into consideration.

\section{Methodology}

Our qualitative approach combined semi-structured interviews with parents and group interviews with children. Due to different levels of language proficiency, and different subjective assessments among the participants, it was essential to conduct personal in-depth interviews instead of a standardized survey. The interview 
guideline for parents and children was composed of four sections. The first section dealt with personal questions, such as language proficiency, describing their daily routine, and contact with family back home. The second section dealt with media usage in Germany compared to back home. The third section dealt with children's media usage (for children these questions were directly, while for parents they were indirectly asked). The final section posed questions regarding problems and restrictions arising from media usage, such as quarrels or family media rules. The guided interviews were conducted from $25^{\text {th }}$ February to $2^{\text {nd }}$ March 2018.

Separate interviews were conducted in order to reduce possible cultural or linguistic barriers and to ensure that the participants were comfortable. The parents were interviewed by an Arabic speaking researcher in their own refugee housing or apartments. All parents spoke Arabic as a first language, with Turkish, Kurdish, English or beginner German as a second. The children, on the other hand, were mostly fluent in German and therefore interviewed in German (also at home) by another researcher and separately from their parents. This was also done to enable both respondent groups to be comfortable to share private information, which would enable a comparison of data later on.

According to information given to us by the Refugee and Integration Office of the City of Erlangen, within the last five years, approximately 2000 people have taken asylum in the city, 600 of which are children under the age of 18. From these 2000 refugees, $37 \%$ are Syrian and $21 \%$ are Iraqi. Using a preliminary questionnaire distributed by the City of Erlangen, we recruited asylum-seeking families in the City of Erlangen (Germany) to investigate their media repertoires. While 20 families might not be representative of the entire refugee population in Erlangen, we used theoretical sampling until saturation was reached; meaning that once no new answers were derived from interviews, further recruitment was halted.

All our interviewed families originated from either Iraq or Syria, spoke Arabic, and have resided in Germany for one to four years. The sample consisted of both couples and single parents, with ages ranging from 20 to 53. Most children were in their final year of kindergarten, in primary or secondary school and were between the ages of four and 18. Since some families included children younger than four years of age, they were not interviewed as they were not able to participate in the group interviews with their siblings. Additionally, the sample included a significant number of disabled children; this was thought to be due to Erlangen's reputation as a medical hub in Bavaria. Finally, it is essential to note that almost all children in the sample owned personal smartphones/tablets or had access to their parents' devices.

The Arabic interview data was transcribed by an Arabic native speaker into English. The now English interview data, and German focus group data, was then coded by three assistant researchers fluent in both English and German using the computer assisted qualitative data analysis software (CAQDAS) MAXQDA 18. The analysis 
followed Mayring's (2000) qualitative content analysis approach, which attempts to systemize qualitative textual analysis in a method similar to quantitative ones: "The main idea of the procedure of analysis is thereby, to preserve the advantages of quantitative content analysis as developed within communication science and to transfer and further develop them to qualitative-interpretative steps of analysis» (1). This includes utilizing a coding agenda built on both deductive and inductive categories. Our coding agenda is made up of six sections: access and participation barriers, attitudes and behaviors, selections and decisions, family media rules, media competencies, and social integration in Germany. Deductive categories are built on surveyed literature while inductive categories were built into the agenda based on repeating patterns linked to the research questions. A pre-test was conducted by all coders to establish intercoder-reliability. The pre-test also proved useful in providing a number of inductive codes and fine tuning the coding agenda to remove redundancies.

\section{Results}

To better understand and classify results regarding media rules, mediation and media literacy, some contextual information on the living and educational situation of our participants is provided. This contextual information additionally answers our first $R Q$ : Which media literacy skills do family members of the Arab Diaspora possess?

\section{Basic situation and context}

The families interviewed come from various educational levels, ranging from those who had finished primary school to a rare few with university degrees. The men in the family generally had a higher education standing (middle or high school, with some even having a B.A.). Most women, aside from one widow with a university degree, had only visited primary school and some were illiterate. While many women described themselves as housewives in their home countries, as well as in Germany now, many men had been employed, e.g. as taxi driver, electrician, house painter, owner of a plastic production company or a small supermarket. In Germany, a few men had already found basic employment, mostly part time. Many were looking for work and were busy with appointments at the employment office and filling out applications.

The command of German varied between beginner levels (A1) and advanced (B2). As with levels of education and work, men were at the forefront since some women could not attend German courses due to having children or infants at home. The children already demonstrated a good command of German and attended Kindergarten, refugee integration classes or after-school child care. Some children said they did 
not know (or forgot) how to write in Arabic as they had not, or only shortly learned it before their escape. For those who spent a significant time during the migration process (on boats or in transition countries), this was the time spent learning their language.

In our sample, we had four families living in refugee housing, with only one private room and a shared bath or computer room, and 16 families that had already been allowed to move into their own apartment, which also depended on legal status. Even though families knew of other Arab families (e.g. neighbours in the refugee housing), contact was scarce and limited to relatives. Regarding hobbies not involving media, parents mentioned going out for walks and shopping, while the children noted sports (football and boxing), shopping, playgrounds, swimming, drawing, reading, board games, and foosball; which was available in some after-school childcare institutions and youth clubs.

The families were well equipped with media devices; some stating that they owned more devices now than back in their home countries. The devices were often quite new, and the families were rather technology savvy, e.g. they knew the intricacies and how to operate a smart TV, tablets and smartphones. Elder children often owned personal mobile phones and younger ones had tablets, which some had to share with their siblings. Many families utilize satellite television, allowing them to watch Arabic channels not regularly available in Germany. The families that owned books sometimes had received them from educational institutions, borrowed them from the public library (of the city or school) or bought them. As there was no internet access in some of the refugee housing, they bought data packages for their phones. For that specific reason, one family noted that they did not buy a laptop for their children since they could not use the internet as long as they lived in refugee housing. Once they were allowed to move, they would then make the purchase. Overall, media spending was quite sparse. No money was spent on purchasing actual content such as movies, music or streaming subscriptions. However, families spent around 15 Euro monthly per person for a mobile phone data package, and some had to pay additional satellite subscriptions.

\section{Independent use, barriers and restrictions}

The regulation of media usage is strongly connected to the subjective feeling of autonomy and to possible barriers and restrictions. Concerning disabled children in our sample, some of them were bedridden and could neither speak nor move their hands properly, so it was the parents or the siblings that decided if (and what) they watched on TV or listened to. In the same regard, there were also wives who were dependent on their husbands or children, because it was the husband who controlled the Facebook account, or the children who were more media savvy, e.g. in operating the 
PlayStation or certain apps. Actually, the children showed quite self-sufficient use of their media; having no problems with downloading apps on their mobile phones or using WhatsApp to communicate with their peers.

The most often mentioned barrier that prevented both children and adults from using media was education related. Parents have to attend various language and integration courses, while the children often go to school all day and afterwards have to study for the next day.

Father (40 years, from Syria): «lt's impossible to watch a series every day for an hour because there is so much work to do, appointments with the municipality, colleagues, ... here in Germany time planning is everything.»

Another barrier to usage is the command of language. Parents whose German is not good enough mentioned that they are not able to follow local video or audio media programming. On the other hand, children mentioned that they stopped writing their friends in their home country because they were not used to the Arabic script.

Son (15 years, from Iraq): "So, now I've written so much in German. I write mostly in German and I can now write quickly in German. That's why, if I write in my language [Arabic] by the time I get a sentence out, which really takes long, I am really fed up with this ... That's why I do not have so much contact with them [the old friends].»

Other barriers to access include: illiteracy, preventing some refugees from reading the news (be it online or in a newspaper), or the sharing of only one room for the whole family in the refugee housings, preventing parents from watching TV when their little children are already asleep. Finally, technical barriers such as prohibition by the landlord to install a receiver, and power outages in Iraq and Syria, which limit phone communication with families at home to text messages instead.

\section{Connectivity and routine}

The connection to relatives at home is the most important one for migrants. Yet, they are also connected to other refugees in Germany or in other European countries, and also to Germans. Above all, children talked in excess about their German friends with whom they keep contact via WhatsApp (texting, voice messages, pictures) and Facebook messenger. They also call each other and take part in school WhatsApp groups when available. Adults also mentioned using apps such as WhatsApp, Messenger, Viber, Imo and Facebook for communicative purposes. They now substitute the former face-to-face communication and regular visits back in their home country. 
Mother (33 years, from Syria): «If there was no internet the situation would have been difficult now, at least we could hear the family's news and how they are doing. When we came here the small boy was 1 year old and he didn't know his uncles, but [now] when we video call he sees them and he recognizes them. The internet is like a blessing to us.»

Interviewer: «And do you still communicate with your relatives in Syria?» Father (39 years, from Syria): «Of course, they are living in a hard situation, that is why I have to keep looking through my WhatsApp every two hours to make sure they are well.»

The children mentioned that back in Iraq or Syria, they were busy with visiting relatives and spent a lot of time playing in the streets, not leaving much time for media. Now, in their daily German routine, they use the mobile phone as a remedy for boredom, such as during the ride in the school bus (listening to music, watching YouTube movies, etc.) or on days when the weather is bad. Asked about a weekend deprived of media, they said that they would be extremely bored but mentioned other replacement activities, such as sports and drawing. The refugee children's daily media routine is quite similar to that of German children. TV or iPads in the morning are mostly used on weekends, not before school. After school and dinner, some media use happens either before or after homework, and during free time until the evening. Evening media time is usually spent together with the family watching television, or separately on computers and handheld devices (especially for older children).

\section{Media rules and parental mediation strategies}

Before looking at family media rules, we have to mention that children are also subject to media-related rules at school. There were schools that did not allow mobile phones at all: the children had to place them into a box when entering the building and they were given back at $1 \mathrm{pm}$ after school. Other institutions asked that phones were to be turned off and placed in schoolbags at all times. During school excursions, however, mobile phones were allowed to call parents (e.g. coordinating the return schedule). Children of five families told us explicitly that they had talked at school about media use, dangers of use, and media addiction.

To answer RQ2 - How do parental mediation strategies manifest in Arab Diaspora families? - we follow the abovementioned parental mediation strategies framework, adding an additional aspect: «non-mediated media regulations/little lies» (see below for further explanation). It is interesting to note that most mediation strategies mentioned below are created by the mothers (but enforced by both parents) who are the ones mostly home all day with the children. 


\section{Restrictive mediation (regulations relating to time, device, content, location or purchase)}

Time of media use is restricted for children in almost every family. Restrictions are either regarding number of hours, or period of time. Some families' restrictions are around one to three hours of watching TV per day (after doing homework or studying), while others forbid device usage before going to bed, between the hours of $8 \mathrm{pm}$ and $10 \mathrm{pm}$. On the weekend or during holidays, restrictions were less strict or completely lifted. One father stated he bought the children some PlayStation games during the summer holidays and they were allowed to play them all the time. However, he then took away the PlayStation when school started again. In another family, the iPad was given to the children only on weekends. For a lot of families, the TV was turned off during meals. For others, however, it was a quite central piece in the apartment and meals took place regularly in front of it. Occasionally, an extension of time allocated to media usage was awarded for good grades.

Mother (33 years, from Syria): «Honestly, when we came here I didn't have a problem but I noticed that my children finish their food after 1 hour, and they become so focused that [sometimes] they leave the food.»

Punishment for breaking the rules includes taking the device away or deleting the unwanted program or game. For example, one family found Superman and Disney videos on the device, which are in opposition to their religious and cultural beliefs; choosing to delete them. However, they allowed the children to watch Arabic movies instead, in hopes of strengthening cultural values. Some children were required to put away their mobile phones while doing their homework, others (however only few) while they slept. Younger children (beginning of primary school) were not yet allowed to own mobile phones, or the functionality of their phones was restricted (no internet access).

Interviewer: «Do you allow them to use social media?»

Father (33 years, from Syria): «After she (12 years) comes back from school we have lunch together, and she's only allowed to use it for one hour when I am in the house, but when I am outside, she exceeds the one hour.»

Father (35 years, from Syria): "Once they ( 8 and 5 years) downloaded the Ninja Turtles game and it contains violence, so it told them 'if I saw it one more time I will take the iPad from you.'» 


\section{Active mediation (instructive or evaluative conversations; participatory learning)}

Studying was noted as the most important reason for limiting media usage by children. This was unequivocally repeated both by parents and children. If the TV, iPad or mobile phone is available, children focus too much on the device and get distracted from learning. This understanding is a result from conversations held between both parties. Additionally, parents explained to their children that they have to get enough; sleep that is why they have to stop using the devices at a certain time in the evening.

In regard to content, parents also actively discussed and instructed their children on the types of content which they should avoid. Some parents instructed their children to avoid sexual content, and for those stemming from extremist backgrounds, even kissing in cartoons was seen as a threat to their religious values.

Father (38 years, Iraq): «For example, they show things that aren't good for kids in cartoon movies ... sexual things.»

Even though in many families, sexual content was more condemned than violence, there were also parents that did not like their children to watch horror, action or excessively violent movies. Images of war or violent games, and content on Facebook was especially frowned upon since multiple families had experienced real war and did not want their children to be reminded of this, or be made aware of what their relatives might be experiencing.

Father (38 years, from Iraq): «When the small boy (7 years) is watching I have to keep an eye on him and it's impossible for him to watch violent movies because we escaped from violence.»

Other active mediation practices included that parents ask their children about what they downloaded. If it was an inappropriate game that had to be removed; they explained why. If inappropriate content appeared on TV, the parent changed the program. One mother told us that she always accompanied her sons (primary school) to the game store so that they did not buy games unsuitable for their age. One adolescent told us that their parents had told her to notify them if she watched an inappropriate video at school so that they could talk to the teacher.

\section{Distant mediation (supervision, deference: e.g. while housekeeping)}

Many parents observed their children directly (sitting beside them) or indirectly (giving a look here and there while doing housework) during children's media time: especially younger children. Some tried to do it as unobtrusively as possible, so as to not let their children feel controlled. However, some also said they trusted their children, or at least hoped they did not use their devices for pornographic content. 
Co-use with children or with parents as a «helper» was only marginally mentioned. However, watching something together with parents or siblings («buddy») was mentioned more frequently.

Single mother (32 years, from Syria): «The situation must be controlled. So, I always try as best I can to give them advice and watch what they do and certainly within the acceptable limits so as not to make them feel restricted.»

Even though distant mediation was quite often mentioned, there were also parents that did not intervene at all in media matters:

Interviewer: «What does your son do with the phone?»

Father (35 years, from Iraq): «He (14 years) uses it for communication and Facebook, I don't know what he does exactly. These are private things.»

Non-mediated media rules: «little lies»

Parents' non-mediated media regulations include taking the children's devices when they were asleep or not present and checking conversations, downloads or Instagram accounts. Children told us that they knew about various restricted devices, e.g. the smart TV password, as well as telling us about clandestine media use:

Son (12 years, from Iraq): «When my mother goes to bed at around midnight, she usually takes with her our devices. But sometimes she just takes the laptop, so my brother and I used my iPad.»

Other non-mediated issues include broken devices or technical incidents which serve as little lies to mask regulation, making it easier for the parents:

Father (33 years, from Syria): «I cut the Internet on purpose and tell her that it's gone.»

Finally, while parents try to discourage their children from certain content, they do partake in it themselves. So, one little lie is that most parents do not partake in violent content; wanting to support the rules they set themselves. They watch these movies when younger children have fallen asleep.

On the other hand, little children sometimes unknowingly set non-mediated, media-centric rules as well. One family, who lived in a single-room (refugee housing), told us that their three-year-old daughter always cries if the iPad and TV were not turned on simultaneously to cartoon movies. While another family stated that their child only fell asleep while watching TV. 


\section{Media critique}

We asked families what they think about German media laws, what were their worries and concerns regarding media usage (especially in regard to their children). Many said they did not have any concerns and considered the German media laws to be fair (if they knew of any) e.g. age restrictions for content. However, several parents critiqued inappropriate programming in the early evening (e.g. sexual relations, bare skin) and advertising, especially on YouTube, annoyed some children. Furthermore, some parents had issues with specific messages being communicated in cartoons and other content targeted to children. One participant noted that there are messages promoting unhealthy behaviours and values to children:

Father (47 years, from Syria): «l am aware enough to differentiate between the good and the bad. But it's hard for the children especially those who are two years old. For example, there is a cartoon movie where the mother gives the baby some vegetables, the baby takes the plate and throws it, and then he takes unhealthy food. I saw many movies like these. They're not suitable for children.»

Other parents that had major media critiques did so not only due to content but also due to frequency of usage.

Father (33 years, from Syria): «If I let the children use the phone as they please then it'll be bad for them.»

His wife (33 years, from Syria): «l know that if the child uses the phone for 3 to 4 hours his IQ will reduce by 30 to 40 percent.»

\section{Conclusion}

Our study investigated the media literacy skills and parental mediation strategies in relation to media repertoires of 20 families that had fled their war-torn countries of Iraq and Syria and sought asylum in the City of Erlangen, Germany. Having resided there between three to four years, both the parents' and children's media repertoires (content/device) underwent drastic changes. This led to a variety of mediation strategies being applied.

Similar to Belgians (Zaman et al. 2016), Arab refugees in our study applied three core parental mediation practices: restrictive, active and distant intervention. Using a media repertoire perspective, we were able to observe that parents regulate both their children's content and device repertoires. This was done either through limiting the number of devices, taking them away, restricting them with passwords, or controlling the content the children were allowed to watch and use. For more lenient parents, an additional intervention strategy was found: non-mediated media rules, 
or «little lies», where parents would lie to their children about devices not functioning to spare them having to restrict access. This strategy is a prototypical example of a novel media related agency. Under certain conditions, refugees are more than able to regulate their media usage effectively, and in a meaningful way (see in more detail Friedrichs-Liesenkötter and Schmitt 2017). Alternatively, younger children would enforce non-mediated, media-centric rules by acting out if not getting their way with their devices. Arab refugee parents, however, did not apply co-use mediation strategies as often as other Belgian parents in Zaman et al.'s (2016) study, which we attribute to their lack of media skills and knowledge.

The manifestation of regular mediations noted in literature (Zaman et al. 2016) is similar to European families, such as limiting time of media device usage to certain periods during the day, or to a number of hours per day, or even location, e.g. not at the dinner table. However, the reasoning behind certain interventions is influenced by religious and cultural values which might not be as common in certain European cultures. While it was not the case for every family, several of those interviewed stated that sexual content was completely inappropriate for their children; the greatest danger for them, and the most likely reason for intervention. This can usually be attributed to cultural norms, or diverse religious values. In other cases, the culprit was violence. In many refugee families, it appears that the trauma experienced during their flight was so great that they do not want to expose their children to similar events.

In addition to cultural and religious values, education plays a role in mediation strategies, both in how they are enforced and the reasoning behind them. Most mediation strategies are applied due to the children's need to study. This is either done restrictively, by having their devices taken away from them, or through conversation and explanation. Also, the reasoning for parental mediation strategies is largely due to the parent's level of education. As the examples above have pinpointed, in our sample, we observed that Arab refugee parents are either more lenient or extremely strict without distinguishing between media. For example, parents will ban device usage without considering the need of the device for homework, e.g. YouTube tutorials, school online platforms or the like. They do not see the benefit of media for productivity, learning or studying. Additionally, their beliefs of the harms that media bring are built on assumptions that are not backed by science or fact; leading to harsher punishment or stricter intervention for those who do mediate.

Coming back to Baacke's (1997) framework on users' media literacy, one thing has to be emphasized. Our results hint that most parents miss profound knowledge in the areas critique, knowledge, usage, and production concerning German media. This is due to the fact that although adults can access German-language media content (some do it to improve their language skills), most of the content they access is in Arabic. All information about the host country (and German media) is mostly 
collected in Arabic. That said, young people show a greater self-confidence and selfevident handling of media and its contents. However, this is not necessarily accompanied by a more critical and reflected media practice.

Looking further at the question of how media and communication could contribute to the integration of ethnic minorities, we suggest that enabling children and adolescents to competently make use of various media devices and content should be part of any integration effort. Language cartoons in which the social system (values, refuse collection, school routines, etc.) is explained, and which are sent via a town's YouTube channel, might be a first step.

\section{Limitations}

In the end, it is important to critically reflect on our study. What does it say about the agency of media as well as of the refugees? This study is based on the subjective perception of the interviewees, not on observed real-world practices per se. It is possible that there is a level of social desirability and that parents only wanted to relay qualities which would reflect well on them. Hence, their mediation strategies could be far less lenient than stated here. Also, the socioeconomic status of those interviewed in our study is of a specific level, so, it should be stated that Arab migrants of other socioeconomic levels could have completely different parental mediation practices; ones that might reflect different values and are not restricted as much by cultural and religious issues. However, we would expect similar findings in towns that are similar in size, region, and technological (e.g. net coverage) as well as public service equipment (e.g. public libraries).

\section{References}

Amt für Statistik. 2017. «Einwohnerinnen Und Einwohner mit Migrationshintergrund am Ort der Hauptwohnung in Berlin am 31.12.2014 nach LOR 1 und ausgewählten Herkunftsgebieten». Potsdam, Berlin-Brandenburg.

Arnold, Sina, Stephan Oliver Görland, and Samira Abba. 2017. «Digitalisierung und selbstorganisierte migrantische Logistik». Solidarität im Wandel?: 286-96. Berlin. https://www.bim. hu-berlin.de/media/Forschungsbericht_BIM_Fluchtcluster_23032017.pdf.

Baacke, Dieter. 1997. Medienpädagogik. Grundlagen der Medienkommunikation. Band I. Tübingen

Bulger, Monica, and Patrick Davison. 2018. «The Promises, Challenges, and Futures of Media Literacy». Journal of Media Literacy Education, 10 (1), 1-21.

Díaz Andrade, Antonio, and Bill Doolin. 2016. «Information and Communication Technology and the Social Inclusion of Refugees». MIS Quarterly 40 (2): 405-16. https://doi. org/10.25300/MISQ/2016/40.2.06. 
Diminescu, Dana. 2008. «The Connected Migrant: An Epistemological Manifesto». Social Science Information 47 (4): 565-79.

Fiedler, Anke. 2016. «Information to Go: Kommunikation im Prozess der Migration am beispiel Syrischer und Irakischer Flüchtlinge auf Ihrem Weg Nach Deutschland». Global Media Journal 6 (1).

Friedrichs-Liesenkötter, Henrike, and Caroline Schmitt. 2017. «Digitale Medien als Mediatoren von Agency: Empirische Einblicke in Medienpraktiken junger Geflüchteter und die (medien-) pädagogische Arbeit». Medienimpulse 3/2017.

Gajjala, Radhika. 2004. Cyberselves: Feminist Ethnographies of South Asian Women. Walnut Creek, CA: AltaMira Press.

Hasebrink, Uwe, and Andreas Hepp. 2017. «How to Research Cross-Media Practices? Investigating Media Repertoires and Media Ensembles.» Convergence: The International Journal of Research into New Media Technologies 23 (4): 362-77. https://doi. org/10.1177/1354856517700384.

Hasebrink, Uwe, and Jutta Popp. 2006. «Media Repertoires as a Result of Selective Media Use. A Conceptual Approach to the Analysis of Patterns of Exposure». Communications 31 (3): 369-87.

Hedge, Radha S. (ed.). 2011. Circuits of Visibility: Gender and Transnational Media Cultures. New York: NYU Press.

Hopkins, Nicolas S., and Saad Eddin Ibrahim. (ed.). 2006. Arab Society: Class, Gender, Power \& Development. Cairo: The American University in Cairo Press.

Horst, Heather A., and Erin B Taylor. 2014. "The Role of Mobile Phones in the Mediation of Border Crossings: A Study of Haiti and Dominican Republic». The Australian Journal of Anthropology. 25(2). 155-170.

Hurrelmann, Klaus, and Ullrich Bauer. 2018. Socialisation During the Life Course. London/New York: Routledge.

Jandura, Olaf, Manuel Wendelin, Marian Adolf, and Jeffrey Wimmer. (ed.). 2017. Zwischen Integration und Diversifikation. Medien und gesellschaftlicher Zusammenhalt im digitalen Zeitalter. Wiesbaden: Springer VS.

Kutscher, Nadia, and Lisa-Marie Kreß. 2018. «Digitale Medien bei Geflüchteten». In Handbuch Soziale Arbeit mit geflüchteten Kindern und Familien, by L. Hartwig, G. Mennen, and C. Schrapper, 739-44. Weinheim/Basel: Beltz Juventa.

Livingstone, Sonia. (ed.). 2011. Media Literacy: Ambitions, Policies and Measures. Brussels, Belgium. ISBN 9782960115727.

Mayring, Philipp. 2000. «Qualitative Content Analysis». Forum Qualitative Sozialforschung / Forum: Qualitative Social Research 1 (2), [28 Paragraphs].

Molnár, Kay Magdalena. 2008. Am Anfang war das Bild. Medienerziehung im Kindergarten am Beispiel der Aktiven Fotoarbeit. Stuttgart: Ibidem Verlag.

Parham, Angel Adams. 2004. «Diaspora, Community and Communication: Internet Use in Transnational Haiti». Global Networks 4: 199-217. 
Paus-Hasebrink, Ingrid, and Uwe Hasebrink. 2018. «Mit Medienkompetenz gegen Falschinformation?» Aviso 66: 6.

Richter, Carola, Marlene Kunst, and Martin Emmer. 2016. «Flucht 2.0: Zur Forschung mit/über Flüchtlinge und ihre Mediennutzung.» Global Media Journal - German Edition 6(2016) (1).

Rinnawi, Khalil. 2012. «'Instant Nationalism' and the 'Cyber Mufti': The Arab Diaspora in Europe and the Transnational Media». Journal of Ethnic and Migration Studies 38 (9): 1451-1467.

Valkenburg, Patti M., Marina Krcmar, Allerd L. Peeters, and Nies M. Marseille. 1999. «Developing a scale to assess three styles of television mediation: Instructive mediation, restrictive mediation, and social coviewing.» Journal of Broadcasting and Electronic Media 43 (1): 52-67.

Witteborn, Saskia. 2015. «Becoming (Im)perceptible: Forced Migrants and Virtual Practice». Journal of Refugee Studies. 28 (3): 350-367.

Wilding, Raelene. 2006. "“Virtual” Intimacies? Families Communicating Across Transnational Contexts». Global Networks 6: 125-142.

Zaman, Bieke, Marije Nouwen, Jeroen Vanattenhoven, Evelien de Ferrerre, and Jan Van Looy. 2016. «A Qualitative Inquiry into the Contextualized Parental Mediation Practices of Young Children's Digital Media Use at Home». Journal of Broadcasting \& Electronic Media 60 (1): 1-22.

\section{Acknowledgement}

The research for this paper was partly financed by City of Erlangen, Germany, and the FuLM e.V., Ilmenau, Germany. We would especially like to thank the Refugee and Integration office as well as the AWO of Erlangen. 